\title{
Tropical phytoplankton species and pigments of continental shelf waters of North and North-West Australia
}

\author{
G. M. Hallegraeff and S. W. Jeffrey \\ Division of Fisheries Research, CSIRO Marine Laboratories, G.P.O. Box 1538, Hobart, Tas. 7001, Australia
}

\begin{abstract}
The phytoplankton of the shelf waters of the Gulf of Carpentaria, Arafura Sea, Timor Sea and North-West Australia is basically a diatom flora, distinctly different from the oceanic, predominantly dinoflagellate flora of the Coral Sea and Indian Ocean. Large morphologically elaborate tropical diatoms and dinoflagellates of this shelf region show great species diversity (more than $200 \mathrm{spp}$. identified) and a variety of symbiotic associations ( 28 species-pairs recognised). In contrast, the tropical nanoplankton ( 2 to $20 \mu \mathrm{m}$; mainly small diatoms, prymnesiophytes and dinoflagellates; $70 \mathrm{spp}$.) are remarkably similar in species composition to those of subtropical and temperate Australian waters. Water-column chlorophyll values in both North-West Shelf and Gulf waters ranged from 10 to $55 \mathrm{mg}$ $\mathrm{m}^{-2}$. Nanoplankton accounts for 70 to $97 \%$ of total phytoplankton chlorophyll, except in local diatom or Trichodesmium blooms (30 to $60 \%$ ).
\end{abstract}

\section{INTRODUCTION}

The continental shelf waters of North and NorthWest Australia are areas of high biological productivity. The shallow ( 30 to $60 \mathrm{~m}$ ) Gulf of Carpentaria is the site of a multispecies prawn fishery and the shallow (40 to $200 \mathrm{~m})$ and wide $(200 \mathrm{~km})$ North-West Shelf has a large demersal trawl fishery (Sainsbury, 1979; Bain, 1982). Both Gulf and North-West Shelf waters sustain a high zooplankton biomass (up to $1900 \mathrm{mg}$ dry weight $\mathrm{m}^{-2}$; Tranter and Kerr, 1977; Rothlisberg and Jackson, 1982), but the phytoplankton organisms that support the food chains in these areas are largely unknown. Previous surveys in northern Australian waters and the Java Sea have been restricted to examination of netphytoplankton $(>35 \mu \mathrm{m})$ and spectrophotometric chlorophyll analyses (Allen and Cupp, 1935; Desrosières, 1965; Humphrey, 1966; Humphrey and Kerr, 1969; Markina, 1972; Newell, 1973; Motoda et al., 1978).

An opportunity to study the phytoplankton populations of the North-West Shelf in more detail occurred in June 1980 and 1983 (early winter) and December 1982 (summer), and of the Gulf of Carpentaria and Arafura Sea in March 1982 (autumn). The methodology used (Jeffrey and Hallegraeff, 1980a, b; Jeffrey, 1981; Hallegraeff, 1983) allowed characterisation of the com- plete phytoplankton flora, including many of the delicate flagellates, and the full range of photosynthetic pigments (chlorophylls, carotenoids and chlorophyll degradation products). Tropical inshore communities of the Gulf of Carpentaria and North-West Shelf were clearly distinguished from tropical oceanic phytoplankton communities of the Coral Sea and Indian Ocean.

\section{MATERIALS AND METHODS}

Sampling locations. Fig. 1 shows the location of the stations from which phytoplankton samples were taken, and Table 1 summarises cruise numbers, dates and number of stations occupied. Samples from the North-West Shelf were collected along transects from inshore waters (17 to $40 \mathrm{~m}$ depth) to the edge of the continental shelf (euphotic zone depth $150 \mathrm{~m}$ ). The cruise in the Gulf of Carpentaria and Arafura Sea covered water column depths of 26 to $68 \mathrm{~m}$.

Collection and preparation of samples. Sea water samples for pigment analysis and species identification were collected throughout the upper $150 \mathrm{~m}$ of the water column using 81 Niskin bottles. To determine the proportion of nanoplankton $(<15 \mu \mathrm{m}$ fraction; Hallegraeff, 1981), subsamples were fractionated through $10 \mu \mathrm{m}$-mesh plankton gauze and prepared for 


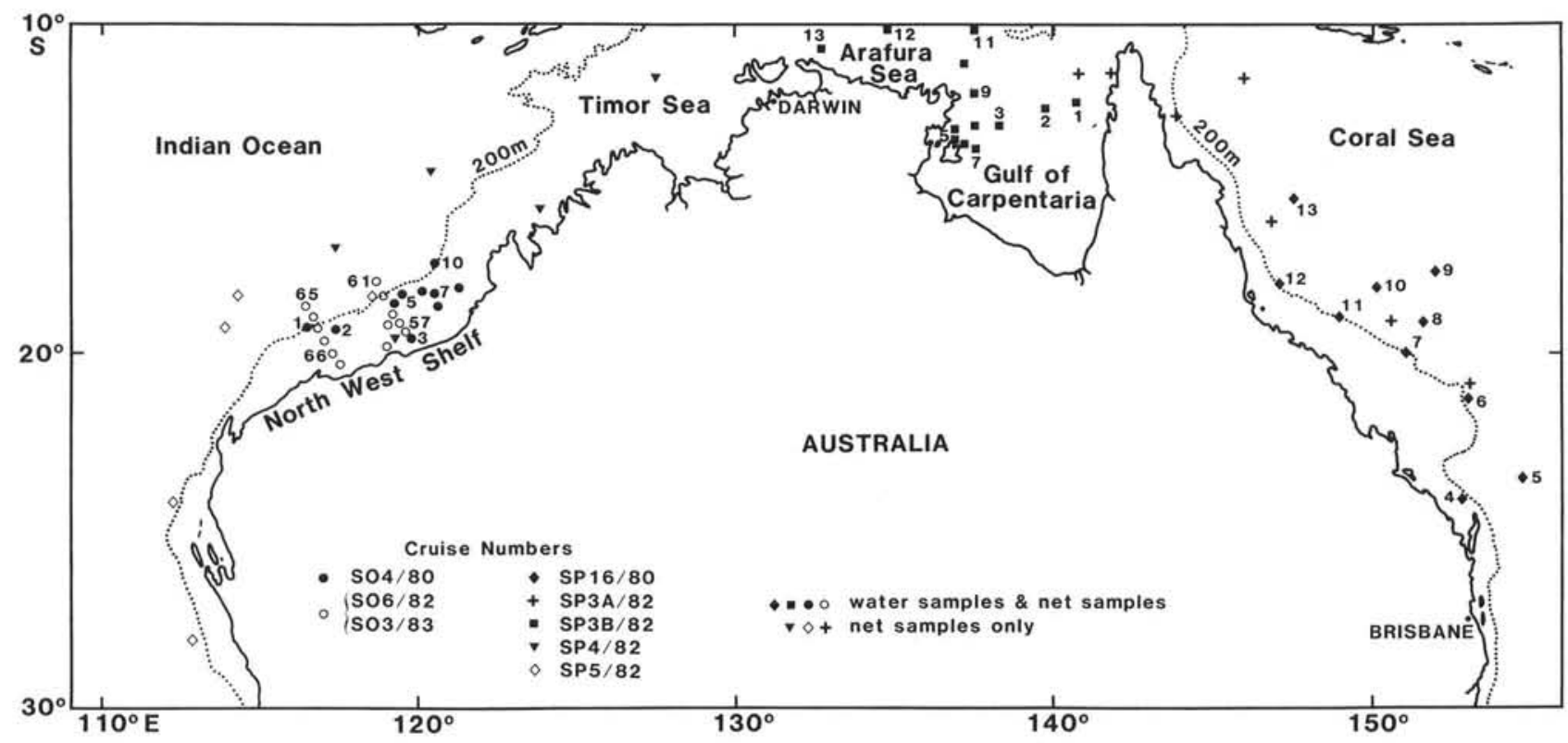

Fig. 1. Map of northern Australia with sampling stations

pigment analysis. Additional collections of the larger phytoplankton species were made with a $37 \mu \mathrm{m}$-mesh free-fall plankton net (Heron, 1982).

Pigment analysis. Chlorophyll a was determined spectrophotometrically from stored and frozen samples (Jeffrey and Humphrey, 1975), followed by separation of all pigment fractions by thin-layer chromatography (Jeffrey, 1981). This method, which uses washed cellulose as adsorbant, separates the major chlorophylls, carotenoids and chlorophyll degradation products in a two-dimensional system that takes only $10 \mathrm{~min}$ per sample.

Species identification. Phytoplankton species were examined microscopically on board ship in the living state. Fluorescence microscopy (using a Zeiss epifluorescence microscope with G436 exciter filter and LP520 barrier filter) was used to distinguish photosynthetic (red or orange fluorescent chloroplasts) from non-photosynthetic algal cells (no fluorescence or golden-green fluorescent cytoplasm). Species abundances were estimated by the inverted microscope technique (Utermöhl, 1958) from water samples concentrated with a continuous-flow plankton centrifuge and preserved with $3 \%$ glutaraldehyde (Jeffrey and Hallegraeff, 1980a). Cell counts were converted to volume estimates by approximating cell shape to the closest solid geometric configuration (Smayda, 1978). Net samples, preserved with $2 \%$ formaldehyde neutralised with hexamine, were used to supplement identification of the larger diatoms and dinoflagellates. Species identifications were achieved by a combination of light microscopy (LM), scanning electron microscopy (SEM) for coccolithophorids, diatoms and armoured dinoflagellates and transmission electron microscopy (TEM) for acid-cleaned diatoms and shadow-cast whole mounts of scale-bearing flagellates. Identification sources were Allen and Cupp (1935); Subrahmanyan (1946) and Simonsen (1974) for diatoms and Taylor (1976) for dinoflagellates. A wide range of individual papers was consulted for nanoplankton (see Hallegraeff, 1983; 1984).

Hydrological measurements. Temperature, salinity and nitrate were measured from water bottle samples using standard methods (Major et al., 1972).

Table 1. Summary of cruises, stations and areas sampled

\begin{tabular}{|llll|}
\hline Cruise no & \multicolumn{1}{c|}{ Date } & Number of stations & Area \\
\hline SO 4/80 & 8-18 Jun 1980 & 10 & North-West Shelf \\
SO 6/82 & 3-16 Dec 1982 & 19 & North-West Shelf \\
SO 3/83 & 14 Jun-1 Jul 1983 & 17 & North-West Shelf \\
SP 3B/82 & 18-30 Mar 1982 & 13 & Gulf of Carpentaria, Arafura Sea \\
SP 16/80 & 5-19 Nov 1980 & 13 & Coral Sea \\
SP 3A/82 & 4-18 Mar 1982 & 5 & Timor Sea, West Coast of Australia \\
SP 4/82 & 22 Apr-5 May 1982 & 5 & West Coast of Australia \\
SP 5/82 & 6ay 1982 & 5 & \\
\hline
\end{tabular}




\section{RESULTS}

\section{Phytoplankton chlorophyll biomass}

Table 2 summarizes the chlorophyll concentrations of all samples taken on the North-West Shelf and the Gulf of Carpentaria and Arafura Sea. Chlorophyll maxima reached $1.07 \mu \mathrm{g} \mathrm{l}^{-1}$ on the North-West Shelf, 2.34 $\mu \mathrm{g} \mathrm{l}^{-1}$ in the Gulf of Carpentaria and $1.26 \mu \mathrm{g} \mathrm{l^{-1 }}$ in the
Arafura Sea. Total water column values in these areas ranged from 10 to $55 \mathrm{mg} \mathrm{m}^{-2}$. The nanoplankton $(<15$ $\mu \mathrm{m}$ fraction) formed a major component of the phytoplankton ( 70 to $97 \%$ of total chlorophyll) in 23 out of 30 stations, whereas the other 7 stations showed values of 30 to $60 \%$ (Table 3 ). Chlorophyll profiles showed deep $(40$ to $80 \mathrm{~m}$ ) maxima in autumn in the central part of the Gulf (Fig. 2a) and in summer on the North-West Shelf when the water column was stratified (Fig. 2b).

Table 2. Concentration of phytoplankton chlorophyll $a$ in continental shelf waters of North and North-West Australia as determined by spectrophotometry

\begin{tabular}{|llll|}
\hline \multicolumn{1}{|c}{ Area } & Month & \multicolumn{2}{c|}{$\begin{array}{c}\text { Chlorophyll a concentration (mean } \pm \text { SD) } \\
\text { Water column maximum } \\
\left(\mu \mathrm{gl}^{-1}\right)\end{array}$} \\
& & $\begin{array}{c}\text { Nater column total } \\
\left(\mathrm{mg} \mathrm{m}^{-2}\right)\end{array}$ & $\begin{array}{c}\text { Number of } \\
\text { observations }\end{array}$ \\
\hline North-West Shelf & Jun 1980 & $36.3 \pm 12.0$ (range 21.9-54.7) & $0.49 \pm 0.18$ (range 0.22-0.69) \\
& Dec 1982 & $27.4 \pm 6.8($ range 10.0-38.1) & $0.60 \pm 0.21$ (range 0.27-1.07) \\
& Jun 1983 & $22.2 \pm 13.3$ (range 7.0-49.7) & $0.43 \pm 0.16$ (range 0.25-0.85) \\
Gulf of Carpentaria & Mar 1982 & $36.1 \pm 8.2($ range 25.8-48.4) & $1.42 \pm 0.56$ (range 0.78-2.34) \\
Arafura Sea & Mar 1982 & $37.5 \pm 3.4$ (range 34.1-40.9) & $1.02 \pm 0.29$ (range 0.70-1.26) \\
\hline
\end{tabular}

Table 3. Nanoplankton $(<15 \mu \mathrm{m})$ chlorophyll at selected stations

\begin{tabular}{llcc|}
\hline Area & Month & $\begin{array}{c}\text { \% of total } \\
\text { water column chlorophyll } \\
\text { (mean } \pm \text { SD) }\end{array}$ & $\begin{array}{c}\text { Number of } \\
\text { observations }\end{array}$ \\
\hline North-West Shelf & Jun 1980 & $84 \pm 9$ (range 67-97) & 10 \\
& Dec 1982 & $64 \pm 4$ (range 60-68) & 3 \\
Gulf of Carpentaria & Jun 1983 & $73 \pm 16$ (range 53-88) & 9 \\
Arafura Sea & Mar 1982 & $72 \pm 21$ (range 30-96) & 2 \\
\hline
\end{tabular}

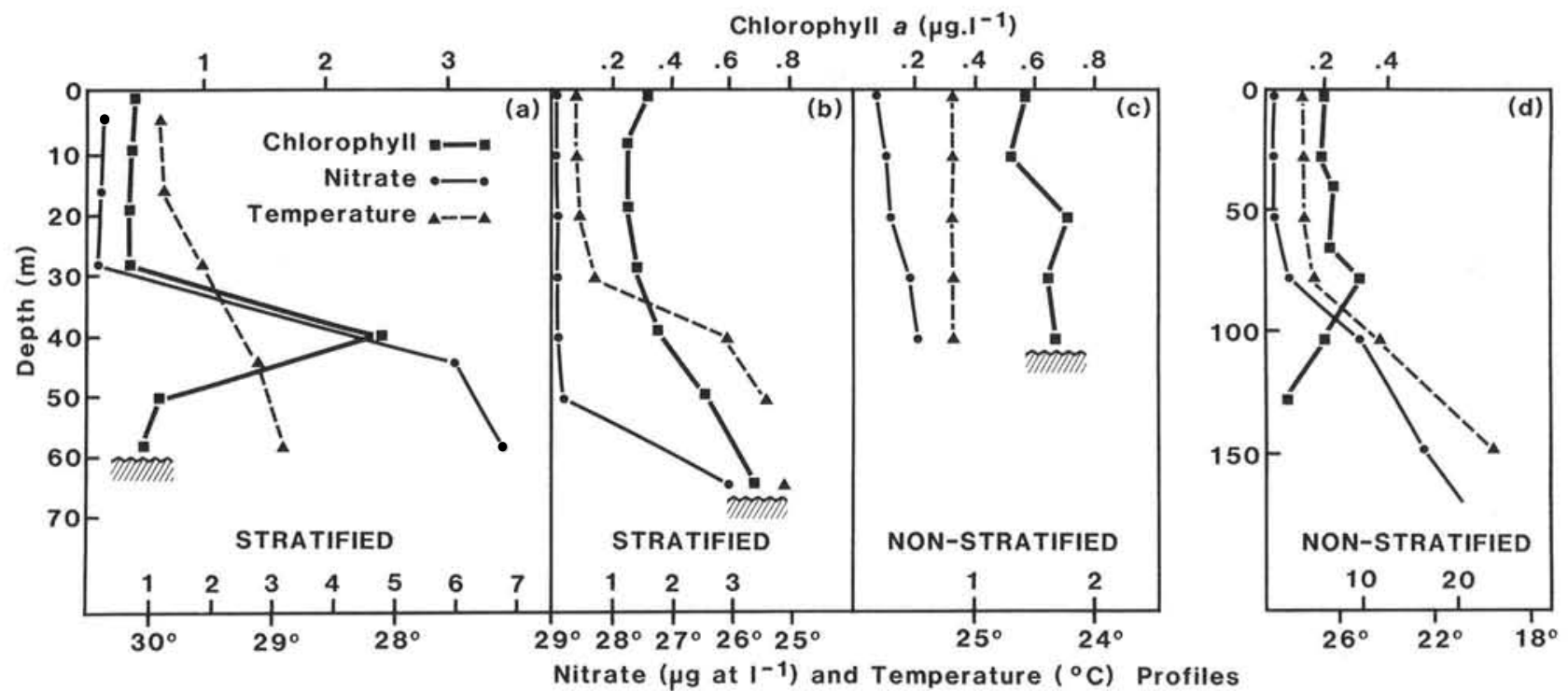

Fig. 2. Typical chlorophyll depth profiles in the Gulf of Carpentaria (a) and on the North-West Shelf (b, c, d) under stratified (a, b) and non-stratified (c, d) conditions, compared with nutrient and temperature structure of the water column. (a) SP 3B/82 cruise, Stn. 2; (b) SO 6/82, Stn. 57; (c) SO 4/80, Stn. 3; (d) SO 4/80, Stn. 10 
Chlorophyll profiles showed an uniform distribution with depth when the water column was well-mixed (Fig. 2c), both in autumn in the Arafura Sea and inshore waters of the Gulf of Carpentaria (Stns. 4, 5, 6) and in winter on the North-West Shelf. Nutrient-rich water $\left(\mathrm{NO}_{3}-\mathrm{N}>3 \mu \mathrm{gat} \mathrm{l}^{-1}\right)$ was always present at the shelf edge at depths below $100 \mathrm{~m}$ (Fig. 2d), but under certain stratified conditions this nutrient layer penetrated into shallower waters, both in the Gulf of Carpentaria (Fig. 2a) and on the North-West Shelf (Fig. 2b).

\section{Phytoplankton pigment composition}

Sixty thin-layer pigment chromatograms were examined from North-West Shelf phytoplankton. Selected examples are shown in Fig. 3a, b, c. Dominant pigments were chlorophyll $a$ and carotene (present in all algal types), fucoxanthin, chlorophyll $C$ (from diatoms and golden brown flagellates), chlorophyll $b$ (green flagellates) and 2 unidentified yellow and 1 pink xanthophyll (Fractions 13, 14 and 15). Trace amounts of peridinin (from photosynthetic dinoflagellates) were present on $20 \%$ of the chromatograms. Small amounts of chlorophyll degradation products were also detected (17 to $19 \%$ of total chlorophyll $a_{\text {; }}$ Table 4) and these were more clearly identified in pooled samples where ample pigment was available for analysis (Fig. 3b, c). Chlorophyll a degradation products detected included pheophytin a (Fraction 5), 1 or 2 unidentified blue-green derivatives (Fractions 6 , 7 ), 1 to 3 chlorophyllide-like zones (Fractions $8,9,10$ ), unidentified brown origin material (Fraction 11) and a pheophorbide-like pigment (Fraction 12). White fluorescent material at the solvent front and sometimes also at the origin of the chromatogram was identified as lipid by staining with iodine vapour. Pigment ratios were estimated by quantitative elution of fractions from three selected chromatograms (Table 4).

\section{Phytoplankton species abundance and diversity}

In terms of cell number, the most abundant species were found in the nanoplankton, the large diatoms and the blue-green alga Trichodesmium were moderately abundant, with the large dinoflagellates less important. Maximum cell concentrations of the nanoplankton ranged from $10^{3}$ to $10^{6}$ cells $1^{-1}$. Small ( 1 to $3 \mu \mathrm{m}$ ) flagellates (e.g. Micromonas pusilla) occurred at maximum concentrations of $10^{5}$ to $10^{6}$ cells $1^{-1}$, small diatoms (Nitzschia bicapitata, Nitzschia closterium, Thalassiosira spp.) at $10^{4}$ to $10^{5} \mathrm{1}^{-1}$, small dinoflagellates (Gymnodinium spp.) at $10^{4}$ to $10^{5} 1^{-1}$ and coc-

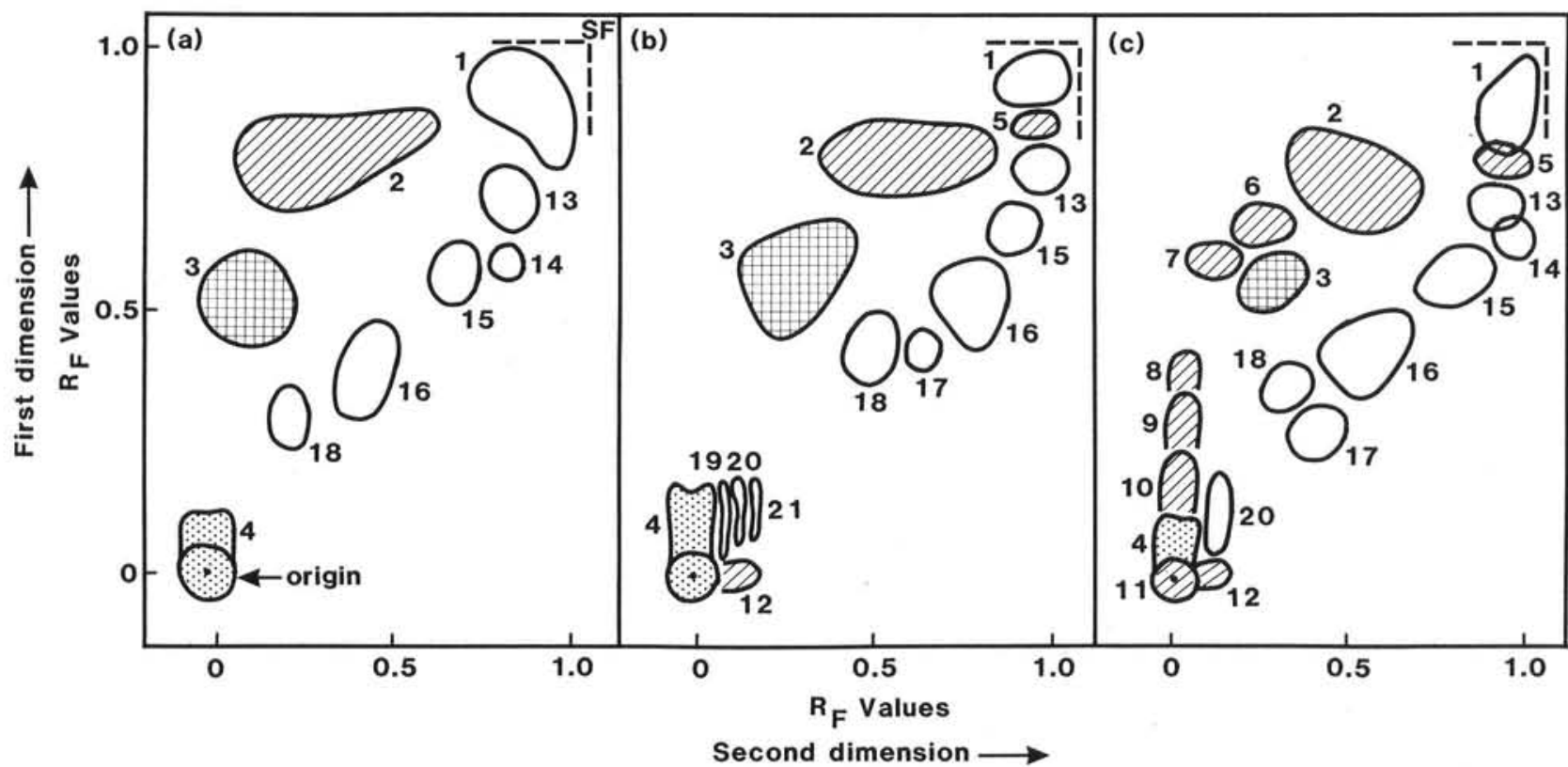

Fig. 3. Cellulose thin-layer chromatograms of photosynthetic pigments from North-West Shelf samples. (A) SO $3 / 83$ cruise, hydrology Stations 10, 11, combined water samples; (B) SO 6/82 cruise, Stns. 62, 63, 64, 67, combined water column samples; (C) SO 4/80 cruise Stns. 4, 9, combined water column samples. Solvent systems, first dimension; n-propanol in light petroleum (60 to $\left.80^{\circ} \mathrm{C}\right), 1.5: 98.5(\mathrm{v} / \mathrm{v})$; second dimension; chloroform, light petroleum, acetone, $20: 80: 0.5(\mathrm{v} / \mathrm{v} / \mathrm{v})$. Pigment fractions: $1:$ carotenes (yellow); 2: chlorophyll a (blue-green); 3: chlorophyll $b$ (olive-green); 4: chlorophyll $c$ (light-green); 5: pheophytin $a$ (grey); 6, 7: unidentified chlorophyll $a$ derivatives (blue-green); 8, 9, 10: chlorophyllide a-like derivatives (blue-green); 11: unidentified chlorophyll a derivative (brown origin material); 12: pheophorbide a-like derivative (grey); 13, 15: unidentified xanthophylls (yellow); 14: unidentified xanthophyll (pink); 16: fucoxanthin (orange); 17: peridinin (red); 18: neofucoxanthin (orange); 19: unidentified xanthophyll (blue); 20: unidentified xanthophyll (orange); 21: unidentified xanthophyll (yellow); SF = solvent front 
Table 4. Relative proportions of photosynthetic pigments in North-West Shelf samples, determined by quantitative elution of pigment fractions from selected chromatograms. (1) SO 4/80 cruise, Stns. 4, 9, combined water column samples; (2) SO 4/80 cruise, Stns. 1, 8, 10, subsurface samples combined; (3) SO 6/82, Stns. 62, 64, 67, combined water column samples

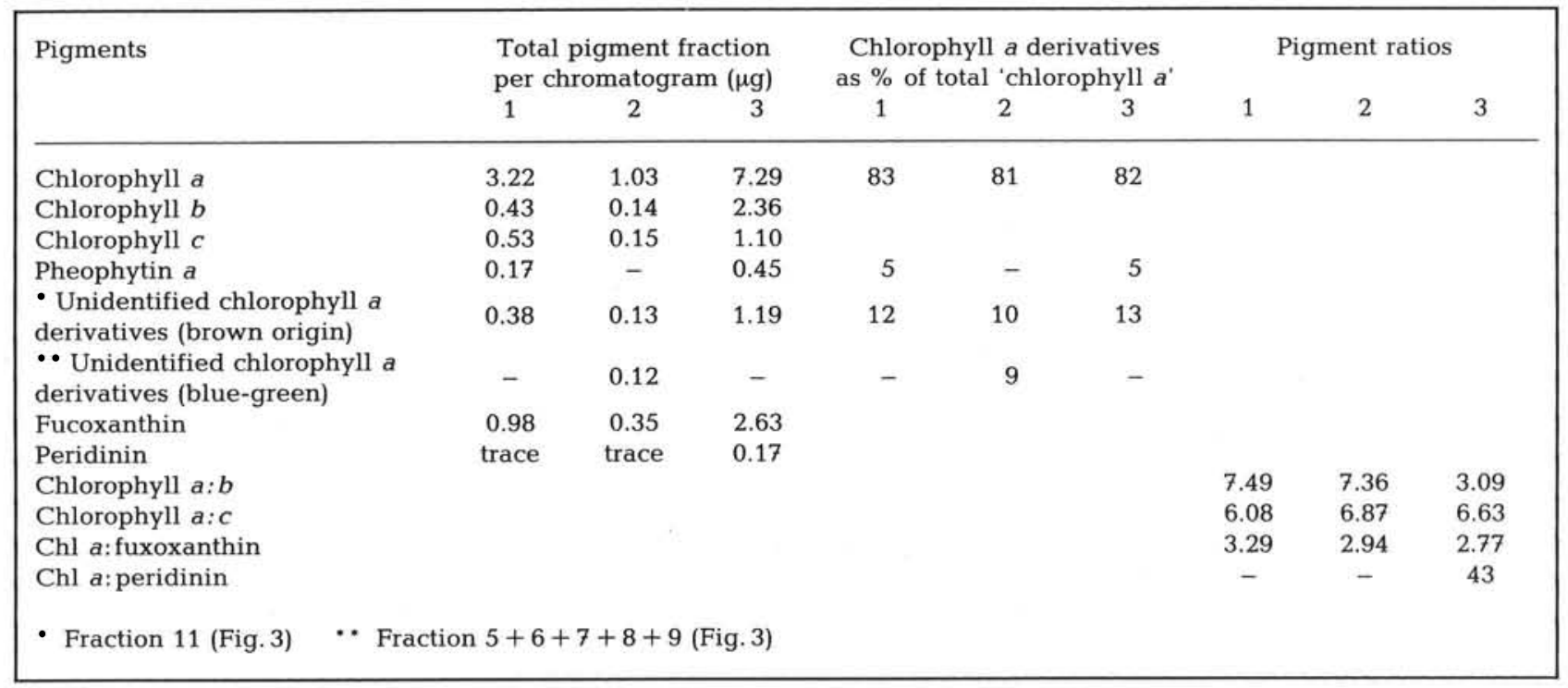

colithophorids (Gephyrocapsa oceanica) and other golden brown flagellates at $10^{3}$ to $10^{4} \mathrm{l}^{-1}$. The larger diatoms were present with $10^{3}$ to $10^{4}$ cells $\mathrm{l}^{-1}$ for Nitzschia species (e.g. N. fraudulenta, N. lineola), $10^{3} \mathrm{l}^{-1}$ for Chaetoceros and Rhizosolenia species, and

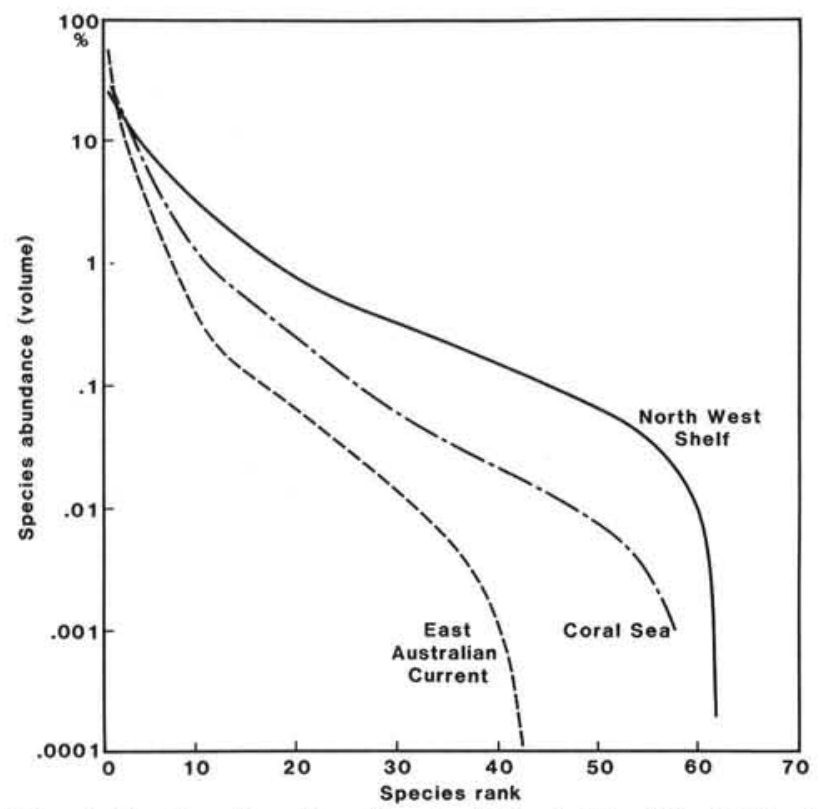

Fig. 4. Species diversity of tropical (North-West Shelf, Coral Sea) and subtropical phytoplankton (East Australian Current), as characterised by dominance-diversity curves. Relative species abundance (by cell volume) plotted on log-scale on ordinate; species ranked from most (rank no. 1) to least abundant (rank no. 63) on abscissa. For each region, watercolumn-integrated cell counts of all species were combined from 7 to 10 different sampling stations. Individual data points have been omitted from graphs for clarity
$10^{2} \mathrm{I}^{-1}$ for Thalassionema and Thalassiothrix species. Local blooms of the blue-green alga Trichodesmium spp. (up to $10^{3}$ trichomes $1^{-1}$ ) were observed in large windrows which extended at times for several kilometres. Large dinoflagellates were less important numerically and occurred with $<10$ cells $1^{-1}$.

Species diversity was characterised by dominancediversity curves (Hallegraeff and Ringelberg, 1978; Jeffrey and Hallegraeff, 1980a). Fig. 4 compares a typical curve of North-West Shelf phytoplankton with curves for Coral Sea and less diverse East Australian Current phytoplankton. Cell numbers were integrated over the water column and relative species abundance (by cell volume) plotted on a log scale on the ordinate, with species ranked from most (rank no. 1) to least abundant (rank no. 63) on a linear abscissa. The NorthWest Shelf samples showed flat sigmoid curves with long intermediate segments, indicative of a great species diversity with both an even distribution of species abundances as well as a large number of species present. A total of 43 to 63 phytoplankton species were recognised per station from water samples, and net samples added a further 5 to 17 species.

\section{Phytoplankton species composition}

The complete phytoplankton species list of all stations in the Gulf of Carpentaria and on the North-West Shelf is given in Table 5 .

A wide variety of nanoplankton $(70$ species) from 8 algal classes was identified from water bottle samples. These included prymnesiophytes (36 spp.), small 
Table 5. Phytoplankton species list of the Gulf of Carpentaria and North-West Shelf samples: Diatoms (DIAT, 151 spp.), dinoflagellates (DIN, 112 spp.), prymnesiophytes (PRYM, 36 spp.), chrysophytes (CHRYS, 3 spp.), prasinophytes (PRAS, 4 spp.), cryptomonads (CRYP, 3 spp.), cyanobacteria (CYAN, 2 spp.) and euglenoids (EUGL, 1 spp.)

\begin{tabular}{|c|c|c|c|}
\hline \multicolumn{4}{|c|}{ Dominant and subdominant species ( 1 to $100 \%$ of phytoplankton biomass) } \\
\hline \multicolumn{4}{|c|}{ NANOPLANKTON ( 2 to $20 \mu \mathrm{m})$} \\
\hline Amphidinium sp. & DIN & -Helladosphaera cornifera & PRYM \\
\hline Amphora sp. & DIAT & Hemiselmis sp. & CRYP \\
\hline Anoplosolenia brasiliensis & PRYM & -Meringosphaera mediterranea & CHRYS \\
\hline -Anthosphaera robusta & PRYM & •Minidiscus trioculatus & DIAT \\
\hline Calciopappus caudatus & PRYM & - Michaelsarsia elegans & PRYM \\
\hline •Calciosolenia murrayi & PRYM & -Micromonas pusilla & PRAS \\
\hline Calyptrolithophora gracillima & PRYM & Nanoneis hasleae & DIAT \\
\hline Calyptrolithophora pirus & PRYM & Navicula sp. & DIAT \\
\hline Calyptrosphaera oblonga & PRYM & Nephroselmis pyriformis & PRAS \\
\hline - Caneosphaera molischii & PRYM & - Nitzschia bicapitata & DIAT \\
\hline - Chilomonas marina & CRYP & - Nitzschia constricta & DIAT \\
\hline Cochlodinium sp. & DIN & Nitzschia cf. fonticola & DIAT \\
\hline Corisphaera wetsteinii & PRYM & - Oolithotus fragilis subsp. cavum & PRYM \\
\hline - Coronosphaera mediterranea & PRYM & - Oxytoxum nanum & DIN \\
\hline 'Crenalithus sessilis & PRYM & - Oxytoxum variabile & DIN \\
\hline Cryptomonas spp. & CRYP & -Phaeocystis pouchetii & PRYM \\
\hline - Calcidiscus leptoporus & PRYM & - Pyramimonas obovata & PRAS \\
\hline - Chrysochromulina pringsheimii & PRYM & Pyramimonas sp. & PRAS \\
\hline Chrysochromulina spp. (3) & PRYM & - Rhabdosphaera claviger & PRYM \\
\hline Deutschlandia anthos & PRYM & Scrippsiella sp. & DIN \\
\hline - Dictyocha fibula & CHRYS & -Scyphosphaera apsteinii & PRYM \\
\hline Dictyocha fibula v. regularis & CHRYS & •Syracosphaera lamina & PRYM \\
\hline •Discosphaera tubifer & PRYM & • Syracosphaera pirus & PRYM \\
\hline - Distephanus speculum v, octonarius & CHRYS & - Syracosphaera pulchra & PRYM \\
\hline -Emiliania huxleyi & PRYM & - Thalassionema nitzschioides v. parva & DIAT \\
\hline •Eutreptiella sp. & EUGL & •Thalassiosira allenii & DIAT \\
\hline - Gephyrocapsa ericsonii & PRYM & -Thalassiosira diporocyclus & DIAT \\
\hline - Gephyrocapsa oceanica & PRYM & -Thalassiosira lineata & DIAT \\
\hline - Grammatophora oceanica & DIAT & -Thalassiosira mala & DIAT \\
\hline •Gymnodinium nanum & DIN & •Thalassiosira oceanica & DIAT \\
\hline • Gymnodinium punctatum & DIN & Thalassiosira oestrupii v. venrickae & DIAT \\
\hline -Gymnodinium simplex & DIN & Thalassiosira partheneia & DIAT \\
\hline Gymnodinium spp. & DIN & Thalassiosira subtilis & DIAT \\
\hline Gyrodinium sp. & DIN & Umbellosphaera irregularis & PRYM \\
\hline - Halopappus adriaticus & PRYM & -Umbilicosphaera hulburtiana & PRYM \\
\hline \multirow[t]{2}{*}{ •Helicosphaera carteri } & PRYM & •Umbilicosphaera sibogae & PRYM \\
\hline & & Umbilicosphaera sibogae var. foliosa & PRYM \\
\hline \multicolumn{4}{|c|}{ Dominant diatoms and cyanobacteria } \\
\hline Bacteriastrum comosum & DIAT & - Chaetoceros radicans & DIAT \\
\hline •Bacteriastrum furcatum & DIAT & -Detonula pumila & DIAT \\
\hline Bacteriastrum hyalinum & DIAT & Eucampia cornuta & DIAT \\
\hline Bellerochea horologicalis & DIAT & •Eucampia zodiacus & DIAT \\
\hline •Chaetoceros affine & DIAT & - Lauderia annulata & DIAT \\
\hline - Chaetoceros anastomosans & DIAT & - Nitzschia fraudulenta & DIAT \\
\hline Chaetoceros atlanticus & DIAT & Nitzschia heimii & DIAT \\
\hline Chaetoceros atlanticus v. neapolitana & DIAT & Nitzschia lineola & DIAT \\
\hline Chaetoceros coarctatus & DIAT & - Nitzschia pungens & DIAT \\
\hline Chaetoceros compressus & DIAT & - Rhizosolenia alata & DIAT \\
\hline - Chaetoceros pseudocurvisetus & DIAT & Rhizosolenia alata f. indica & DIAT \\
\hline - Chaetoceros didymus & DIAT & Rhizosolenia bergonii & DIAT \\
\hline Chaetoceros diversus & DIAT & Rhizosolenia calcar-avis & DIAT \\
\hline - Chaetoceros laciniosum & DIAT & Rhizosolenia clevei & DIAT \\
\hline Chaetoceros laevis & DIAT & Rhizosolenia cylindrus & DIAT \\
\hline - Chaetoceros lorenzianus & DIAT & - Rhizosolenia hebetata & DIAT \\
\hline Chaetoceros messanensis & DIAT & Rhizosolenia hyalina & DIAT \\
\hline - Chaetoceros peruvianus & DIAT & - Rhizosolenia imbricata & DIAT \\
\hline
\end{tabular}


Table 5. Continued

Rhizosolenia phuketensis

- Rhizosolenia robusta

- Rhizosolenia setigera

- Rhizosolenia stoltherfothii

- Rhizosolenia styliformis

- Thalassiosira eccentrica

Thalassiosira leptopus

Thalassiosira punctifera

Thalassiosira simonsenii

Actinocyclus ehrenbergii

- Actinoptychus undulatus

Actinoptychus splendens

Actinoptychus trilingulatus aff.

Asterolampra marylandica

Asteromphalus arachne

- Asteromphalus flabellatus

- Asteromphalus heptactis

-Asteromphalus sarcophagus

Amphisolenia asymmetrica

- Amphisolenia bidentata

Amphisolenia thrinax

- Bacillaria paradoxa

Biddulphia tuomeyi

Blepharocysta splendor-maris

Campylodiscus sp.

- Cerataulina pelagica

Ceratium biceps

Ceratium breve

- Ceratium candelabrum

- Ceratium carriense

Ceratium cephalotum

Ceratium contortum

Ceratium contrarium

Ceratium declinatum

Ceratium dens

Ceratium depressum

Ceratium digitatum

- Ceratium furca

- Ceratium fusus

Ceratium geniculatum

Ceratium gibberum

Ceratium gravidum

- Ceratium horridum

Ceratium humile

Ceratium incisum

- Ceratium kofoidii

Ceratium lunula

Ceratium macroceros

- Ceratium massiliense

Ceratium paradoxides

- Ceratium pentagonum

Ceratium platycorne

Ceratium praelongum

Ceratium ranipes

Ceratium schroeteri

- Ceratium setaceum

Ceratium symmetricum

Dominant diatoms and cyanobacteria

$\begin{array}{lll}\text { DIAT } & \text { Thalassiosira sackettii } & \text { DIAT } \\ \text { DIAT } & \text { Thalassiosira spinosa } & \text { DIAT } \\ \text { DIAT } & \text { Thalassionema bacillaris } & \text { DIAT } \\ \text { DIAT } & \text {-Thalassionema nitzschioides } & \text { DIAT } \\ \text { DIAT } & \text {-Thalassiothrix delicatula } & \text { DIAT } \\ \text { DIAT } & \text {-Thalassiothrix frauenfeldii } & \text { DIAT } \\ \text { DIAT } & \text {-Thalassiothrix longissima } & \text { DIAT } \\ \text { DIAT } & \text {-Trichodesmium erythraeum } & \text { CYAN } \\ \text { DIAT } & \text { Trichodesmium thiebautii } & \text { CYAN }\end{array}$

Rare diatoms and dinoflagellates

( 0.0001 to $1 \%$ of phytoplankton biomass)

DIAT

DIAT

DIAT

DIAT

DIAT

DIAT

DIAT

DIAT

DIAT

DIN

DIN

DIN

DIAT

DIAT

DIN

DIAT

DIAT

DIN

DIN

DIN

DIN

DIN

DIN

DIN

DIN

DIN

DIN

DIN

DIN

DIN

DIN

DIN

DIN

DIN

DIN

DIN

DIN

DIN

DIN

DIN

DIN

DIN

DIN

DIN

DIN

DIN

DIN

DIN
- Ceratium teres

- Ceratium trichoceros

- Ceratium tripos

Ceratium tripos v. indicum

- Ceratium tripos v. pulchellum

- Ceratium vultur

Ceratocorys armata

Ceratocorys horrida

Citharistes apsteinit

- Climacodium frauenfeldianum

Cocconeis sp.

- Corethron criophilum

- Corythodinium elegans

- Coscinodiscus concinnus

Coscinodiscus gigas

Coscinodiscus granii

Coscinodiscus janischii

Coscinodiscus jonesianus

Coscinodiscus nodulifer

Coscinodiscus perforatus

- Coscinodiscus radiatus

Coscinodiscus reniformis

Coscinodiscus stellaris

Cyclotella striata

Cymatosira lorenziana

- Dinophysis caudata

Dinophysis circumsutum

-Dinophysis cuneus

Dinophysis doryphorum

- Dinophysis hastata

Dinophysis miles v. indica

- Dinophysis ovum

Dinophysis rapa

- Dinophysis rotundatum

- Dinophysis sphaerica

Diploneis bombus

Diploneis crabro

Diploneis debyii

Diploneis nitiscens

Diploneis weissflogii

- Dissodium asymmetricum

- Dissodium lunula

Ditylum sol

Eunotia sp.

Fragilaria sp.

Gonyaulax birostris

Gonyaulax hyalina

Gonyaulax pacifica
DIN

DIN

DIN

DIN

DIN

DIN

DIN

DIN

DIN

DIAT

DIAT

DIAT

DIN

DIAT

DIAT

DIAT

DIAT

DIAT

DIAT

DIAT

DIAT

DIAT

DIAT

DIAT

DIAT

DIN

DIN

DIN

DIN

DIN

DIN

DIN

DIN

DIN

DIN

DIAT

DIAT

DIAT

DIAT

DIAT

DIN

DIN

DIAT

DIAT

DIAT

DIN

DIN

DIN

- Ubiquitous species also known from Sydney coastal waters 
Table 5. Continued

- Gonyaulax polygramma

Gossleriella tropica

- Guinardia flaccida

Gyrosigma sp.

Hemiaulus sinensis

Hemidiscus cuneiformis

Heterodinium milneri

Heterodinium rigdenae

Histioneis dolon

Histioneis mitchellana

Histioneis pulchra

- Leptocylindrus danicus

- Leptocylindrus mediterraneus

- Licmophora sp.

- Mastogloia rostrata

Neostreptotheca subindica

Nitzschia americana

Nitzschia braarudii

- Nitzschia closterium

Nitzschia fluminensis

- Nitzschia longissima

Nitzschia marina

Nitzschia panduriformis

Nitzschia punctata

Nitzschia sicula

- Nitzschia sigma

- Odontella mobiliensis

Odontella sinensis

Ornithocercus francescae

Ornithocercus heteroporus

- Ornithocercus magnificus

Ornithocercus splendidus

Ornithocercus quadratus

Ornithocercus skogsbergiii

Ornithocercus steinii

Ornithocercus thumii

- Oxytoxum subulatum

Parahistioneis para

Palmeria hardmaniana

- Paralia sulcata

Pinnularia spp.

- Planktoniella sol

Pleurosigma directum

Pleurosigma diversestriatum

Pleurosigma normanii

Rare diatoms and dinoflagellates

( 0.0001 to $1 \%$ of phytoplankton biomass)

DIN

DIAT

DIAT

DIAT

DIAT

DIAT

DIN

DIN

DIN

DIN

DIN

DIAT

DIAT

DIAT

DIAT

DIAT

DIAT

DIAT

DIAT

DIAT

DIAT

DIAT

DIAT

DIAT

DIAT

DIAT

DIAT

DIAT

DIN

DIN

DIN

DIN

DIN

DIN

DIN

DIN

DIN

DIN

DIAT

DIAT

DIAT

DIAT

DIAT

DIAT

DIAT
Pleurosigma sp

Podolampas bipes

Podolampas elegans

Podolampas palmipes

Podolampas reticulata

Podolampas spinifera

Podosira stelliger

- Prorocentrum lima

- Prorocentrum micans

- Prorocentrum rostratum

Prorocentrum triestinum

Protoceratium areolatum

Protoperidinium depressum

Protoperidinium diabolus

Protoperidinium divaricatum

- Protoperidinium divergens

Protoperidinium leonis

Protoperidinium murrayi

- Protoperidinium oceanicum

- Protoperidinium pallidum

Protoperidinium sourniai

Protoperidinium tubum

Pseudoeunotia doliolus

Pyrocystis fusiformis

Pyrocystis noctiluca

- Pyrocystis robusta

- Pyrophacus horologicus

Raphoneis amphiceros

Raphoneis surirella

- Roperia tesselata

- Skeletonema costatum

- Skeletonema menzellii

- Stauroneis membranacea

Stephanopyxis palmeriana

Surirella sp.

Synedra toxoneides

Trachyneis aspera

- Triadinium polyedricus

Triadinium sphaericum

Triceratium pentacrinus

Triceratium broeckii

Triceratium dubium

Triceratium favus

Trigonium alternans

Triposolenia bicornis
DIAT

DIN

DIN

DIN

DIN

DIN

DIAT

DIN

DIN

DIN

DIN

DIN

DIN

DIN

DIN

DIN

DIN

DIN

DIN

DIN

DIN

DIN

DIAT

DIN

DIN

DIN

DIN

DIAT

DIAT

DIAT

DIAT

DIAT

DIAT

DIAT

DIAT

DIAT

DIAT

DIN

DIN

DIAT

DIAT

DIAT

DIAT

DIAT

DIN

- Ubiquitous species also known from Sydney coastal waters

diatoms (15), small dinoflagellates (10), prasinophytes (4), cryptomonads (3), chrysomonads (3), euglenoids (1) and cyanophytes (2).

The diatom and dinoflagellate floras, taken from net samples, were remarkably similar in the Gulf of Carpentaria, Arafura Sea, Timor Sea and NorthWest Shelf. The large (30 to $1000 \mu \mathrm{m})$ diatom flora included Bacteriastrum (3 spp.), Chaetoceros (15), Coscinodiscus (10), Nitzschia (13), Rhizosolenia (13) and Thalassiosira (6). The large dinoflagellate flora included Ceratium (37 spp.), Dinophysis (10), Ornithocercus (7) and Protoperidinium (8). These species exhibit elaborate morphologies. Examples of morphological extremes are the spines of the dinoflagellate Ceratocorys horrida (Fig. 5), the wing-like extensions of the dinoflagellates Ornithocercus steinii (Fig. 6) and Ceratium cephalotum (Fig. 7) and the diatom Planktoniella sol (Fig. 8), and the long setae of the diatoms Bacteriastrum furcatum (Fig. 9) and Bacteriastrum hyalinum (Fig. 10). 

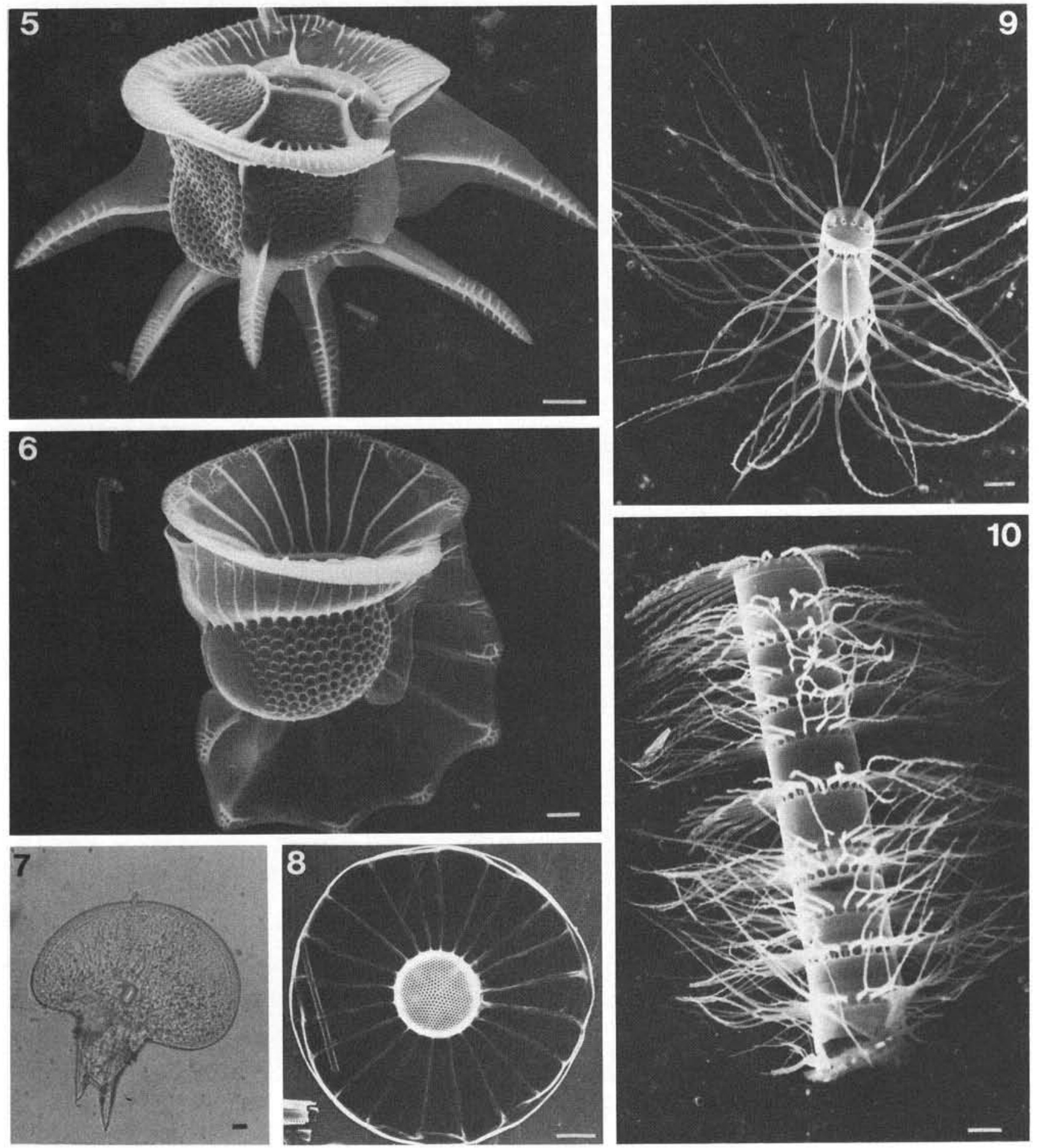

Fig. 5 to 10. Morphological characteristics of tropical dinoflagellates and diatoms (scale bar $=10 \mu \mathrm{m}$ ). 5 : Dinoflagellate Ceratocorys horrida with spine-like extensions of hypotheca. SEM. 6: Dinoflagellate Ornithocercus steinii with wing-like extensions of hypotheca and epitheca. SEM. 7: Dinoflagellate Ceratium cephalotum with enlarged, flattened epitheca. LM. 8: Diatom Planktoniella sol with marginal wing. SEM. 9 and 10: Chain-forming diatoms Bacteriastrum furcatum and Bacteriastrum hyalinum with long setae surrounding the cells 


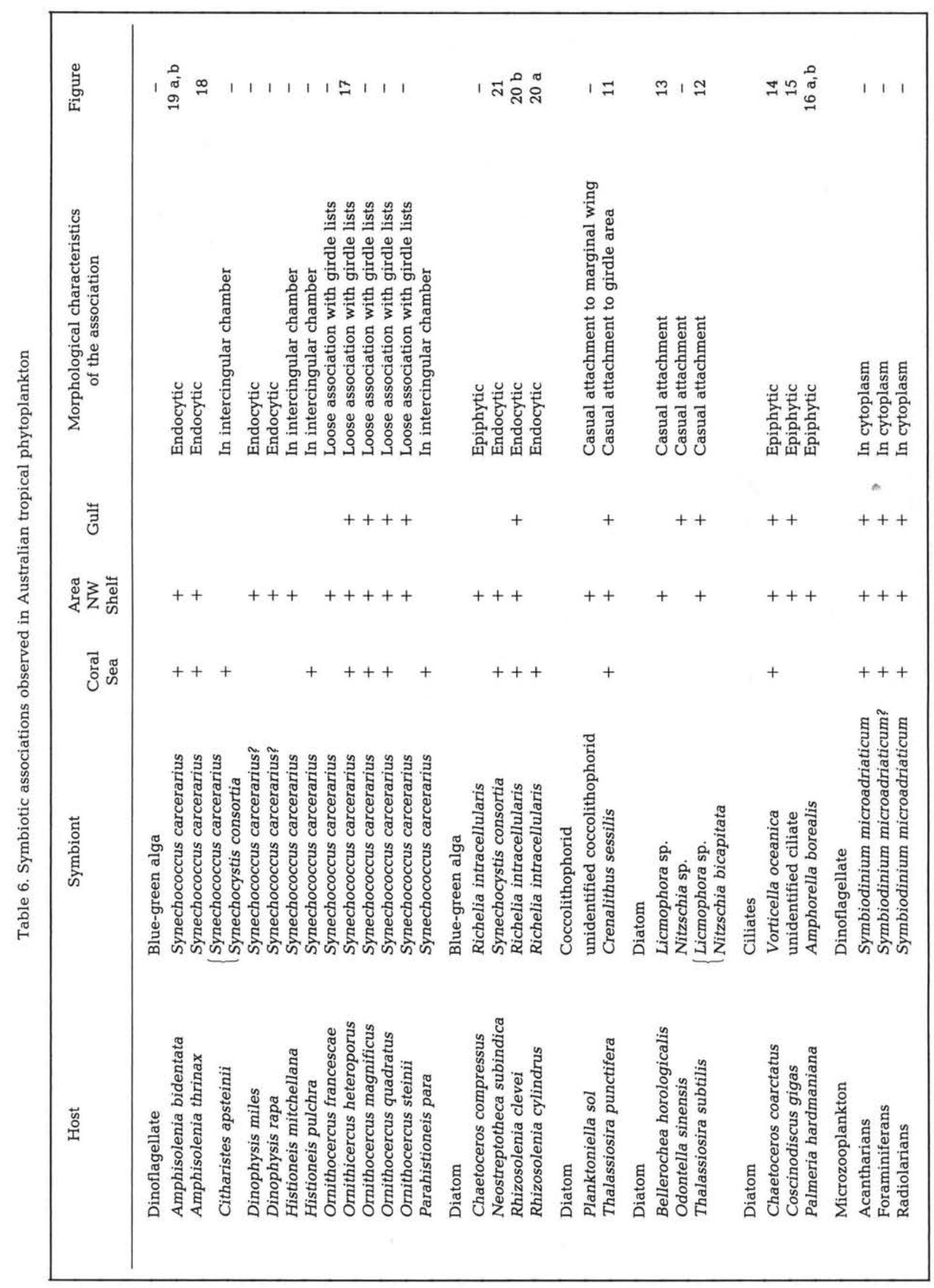



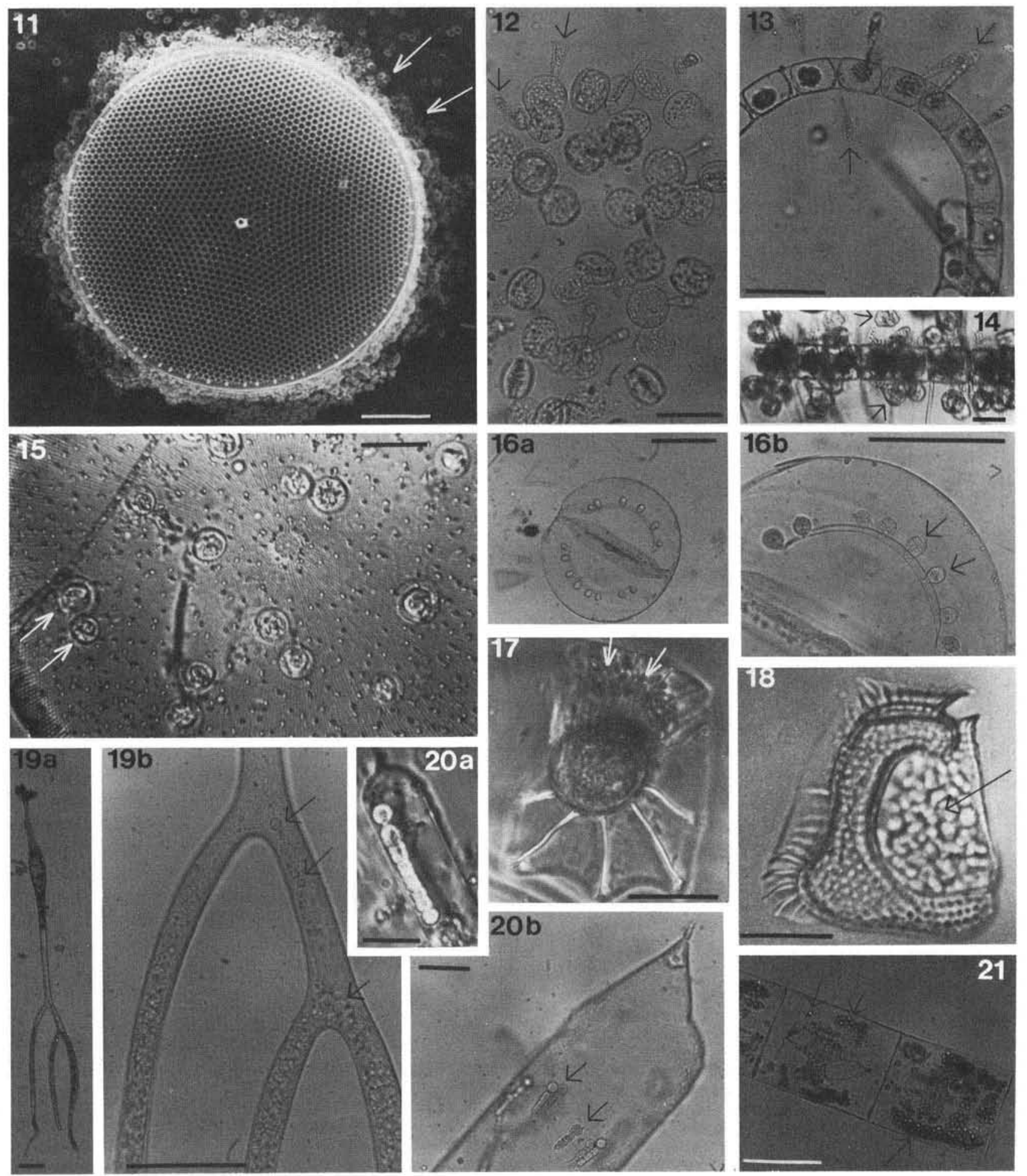

Fig. 11 to 21. Symbiotic associations in Australian tropical phytoplankton. 11: Diatom Thalassiosira punctifera with the coccolithophorid Crenalithus sessilis (arrows) attached to its girdle area; SEM; scale bar $=20 \mu \mathrm{m}$. 12: Gelatinous colony of diatom Thalassiosira subtilis with epiphytic diatom Licmophora sp. (arrows); LM; scale bar $=50 \mu \mathrm{m}$. 13: Chain-forming diatom Bellerochea horologicalis with epiphytic diatom Licmophora sp. (arrows); LM; scale bar $=50 \mu \mathrm{m}$. 14: Chain-forming diatom Chaetoceros coarctatus with epiphytic ciliate Vorticella oceanica (arrows); LM; scale bar $=20 \mu \mathrm{m}$. 15: Partial view of large centric diatom Coscinodiscus gigas with epiphytic ciliates (arrows); LM; scale bar $=100 \mu \mathrm{m}$. 16: a, b: Diatom Palmeria hardmaniana with epiphytic ciliate Amphorella borealis located along 2 hemispherical slits (arrows); LM; scale bar $=50 \mu \mathrm{m}$. 17 : Dinoflagellate Ornithocercus magnificus with blue-green alga Synechococcus carcerarius (arrows) in loose association with girdle lists; LM; scale bar $=50 \mu \mathrm{m}$. 18: Dinoflagellate Citharistes apsteinii with intercingular chamber packed with Synechococcus carcerarius and Synechocystis consortia (arrow); LM; scale bar $=20 \mu \mathrm{m}$. 19: a, b: Dinoflagellate Amphisolenia thrinax with endocytic blue-green alga Synechoccus carcerarius (arrows); LM; scale bar $=100 \mu \mathrm{m}$. 20: (a) Small diatom Rhizosolenia cylindrus with single cell of endocytic blue-green alga Richelia intracellularis; LM; scale bar $=10 \mu \mathrm{m}$; (b) Large diatom Rhizosolenia clevei with numerous Richelia intracellularis (arrows); $\mathrm{LM}_{i}$ scale bar $=100 \mu \mathrm{m} .21$ : Large diatom Neostreptotheca subindica with the endocytic blue-green alga Syncheocystis consortia (arrows); LM; scale bar $=50 \mu \mathrm{m}$ 
Table 7. Fluorescence characteristics of tropical Australian dinoflagellates

\begin{tabular}{|c|c|c|c|c|}
\hline Species & $\begin{array}{l}\text { Photosynthetic } \\
\text { (red chloroplast } \\
\text { fluorescence) }\end{array}$ & $\begin{array}{l}\text { Partially fluorescent } \\
\text { (green fluorescence } \\
\text { with red patches) }\end{array}$ & $\begin{array}{l}\text { Non-photosynthetic } \\
\text { (diffuse green } \\
\text { cytoplasm fluorescence) }\end{array}$ & $\begin{array}{l}\text { Blue-green algal } \\
\text { symbionts (orange } \\
\text { fluorescence) }\end{array}$ \\
\hline Amphisolenia asymmetrica & & & + & \\
\hline Amphisolenia bidentata & & & + & + \\
\hline Amphisolenia thrinax & & & + & + \\
\hline Blepharocysta splendor-maris & & & + & \\
\hline Ceratium biceps & + & & & \\
\hline Ceratium breve & + & & & \\
\hline Ceratium candelabrum & + & & & \\
\hline Ceratium carriense & + & & & \\
\hline Ceratium cephalotum & + & + & & \\
\hline Ceratium contortum & + & & & \\
\hline Ceratium contrarium & + & & & \\
\hline Ceratium dens & + & & & \\
\hline Ceratium depressum & + & & & \\
\hline Ceratium digitatum & + & & & \\
\hline Ceratium furca & + & + & & \\
\hline Ceratium fusus & + & & & \\
\hline Ceratium geniculatum & + & & & \\
\hline Ceratium gibberum & + & & & \\
\hline Ceratium horridum & + & & & \\
\hline Ceratium incisum & + & & & \\
\hline Ceratium kofoidii & + & & & \\
\hline Ceratium limulus & + & & & \\
\hline Ceratium lunula & + & & & \\
\hline Ceratium massiliense & + & & & \\
\hline Ceratium paradoxides & + & & & \\
\hline Ceratium pentagonum & + & & & \\
\hline Ceratium platycorne & + & & & \\
\hline Ceratium praelongum & + & & & \\
\hline Ceratium schroeteri & + & & & \\
\hline Ceratium teres & + & & + & \\
\hline Ceratium trichoceros & + & & & \\
\hline Ceratium tripos & + & & & \\
\hline Ceratium tripos v. pulchellum & + & & & \\
\hline Ceratium vultur & + & & & \\
\hline Ceratocorys horrida & + & + & + & \\
\hline Ceratocorys armata & & & + & \\
\hline Citharistes apsteinii & & & + & + \\
\hline Corythodinium elegans & + & & & \\
\hline Corythodinium tesselatum & + & & & \\
\hline Dinophysis caudata & + & + & & \\
\hline Dinophysis circumsutum & & & + & \\
\hline Dinophysis cuneus & & & + & \\
\hline Dinophysis doryphorum & & & + & \\
\hline Dinophysis miles v. indica & + & & & + \\
\hline Dinophysis ovum & + & & & \\
\hline Dinophysis rapa & & & + & \\
\hline Dissodium asymmetrica & & & + & \\
\hline Gonyaulax birostris & + & & & \\
\hline Gonyaulax pacifica & + & & & \\
\hline Gonyaulax polygramma & + & & & \\
\hline Gymnodinium sp. & + & & & \\
\hline Gymnodinium sp. & & & + & \\
\hline Histioneis mitchellana & & & + & + \\
\hline Histioneis pulchra & & & + & + \\
\hline Ornithocercus francescae & & & + & + \\
\hline Ornithocercus heteroporus & & & + & + \\
\hline Ornithocercus magnificus & & & + & + \\
\hline Ornithocercus quadratus & & & + & + \\
\hline Ornithocercus steinii & & & + & + \\
\hline
\end{tabular}


Table 7. Continued

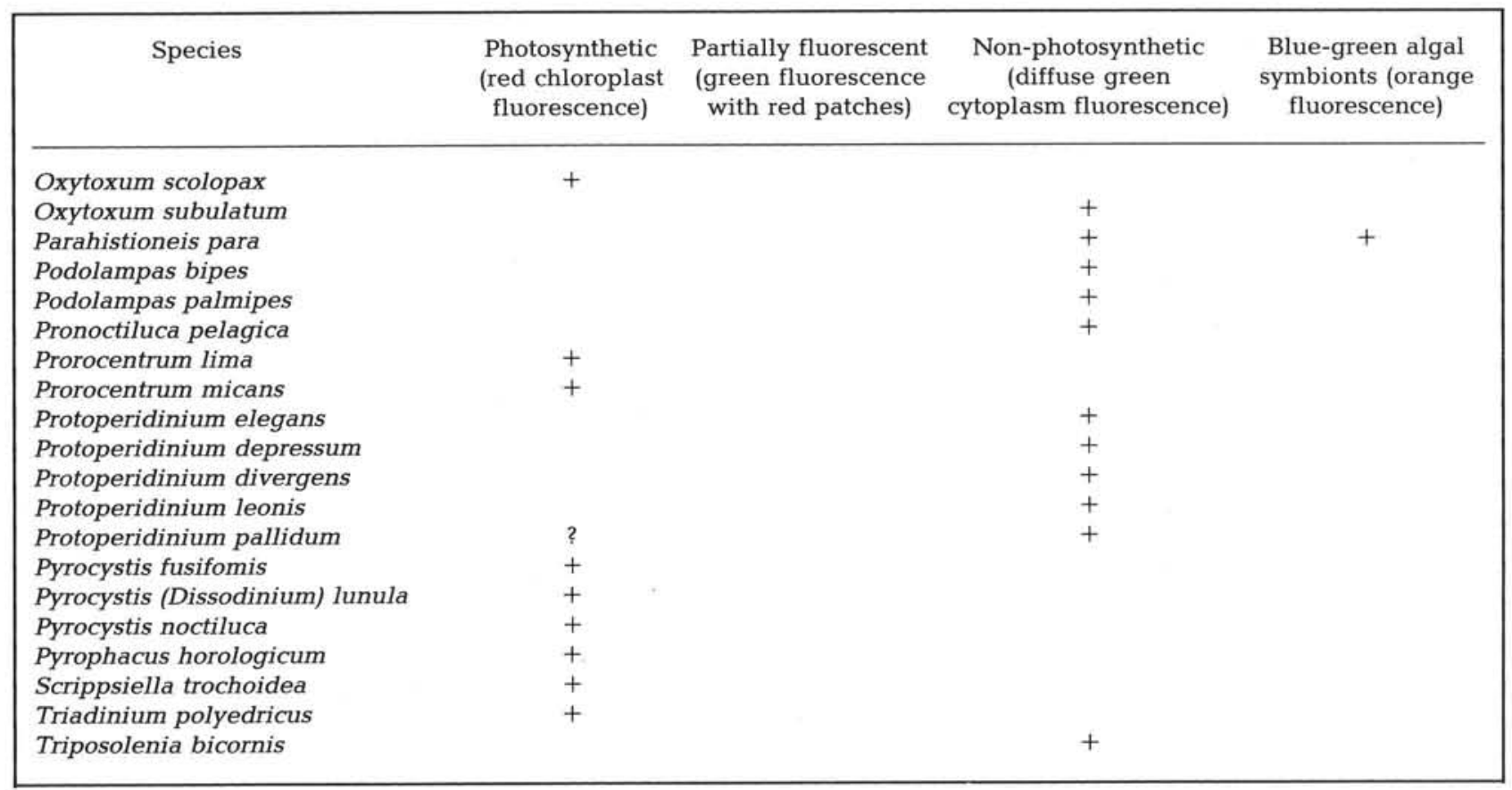

Many symbiotic associations were recognised (Table 6). Twenty-eight associations ranged from casual attachment between diatoms and coccolithophorids (Fig. 11), diatoms and diatoms (Fig. 12 and 13), diatoms and ciliates (Fig. 14, 15 and 16) to more specialised relations (Fig. 17, 18, 19, 20 and 21). The colourless dinophysoid dinoflagellates with winglike extensions often contained orange fluorescent blue-green algae in a possibly symbiotic relation. In Ornithocercus up to 100 symbiotic cells (3 to $8 \mu \mathrm{m}$ diameter) were found extracellularly in the girdle list region (Fig. 17), but in Citharistes and Histioneis similar cells were contained in special chambers (Fig. 18). A specialised endocytic relationship was observed for Amphisolenia (Fig. 19). These blue-green algal symbionts are all thought to belong to the same 2 species Synechococcus carcerarius (spherical cells) and Synechocystis consortia (elongated cells; Norris, 1967), but their ultrastructure is unknown. Some symbionts (e.g. dinoflagellate Symbiodinium microadriaticum, and blue-green Synechococcus carcerarius) occurred with a wide range of host species, but others appeared

SPECIES

AREA

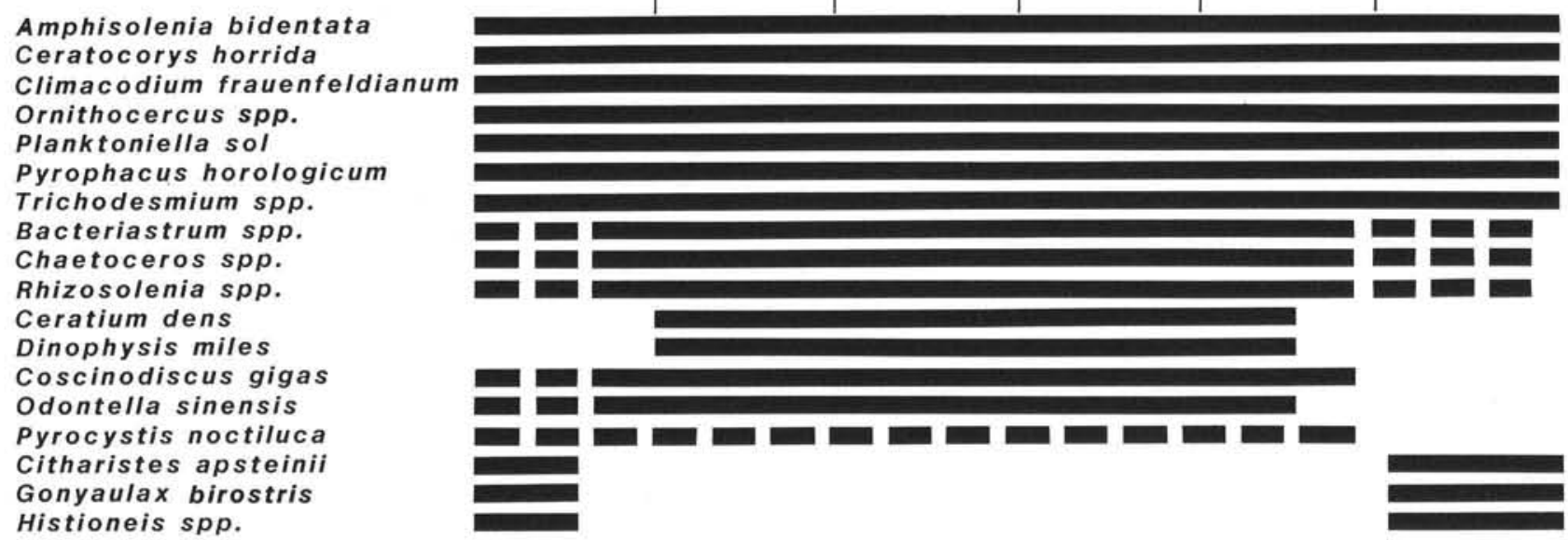

Fig. 22. Distribution of selected tropical phytoplankton species in coastal waters of northern Australia. Solid Bar $=$ common $\left(10^{4}\right.$ to $10^{6}$ cells $\left.\mathrm{l}^{-1}\right)$; broken bar $=$ rare $\left(10\right.$ to $10^{3}$ cells $\left.1^{-1}\right)$ 
to be remarkably host-specific. The coccolithophorid Crenalithus sessilis associated only with the diatom Thalassiosira punctifera, and the blue-green alga Richelia intracellularis only with the diatoms Rhizosolenia clevei and $R$. cylindrus. Symbionts were always present in these species found in tropical waters but the host species were without their symbionts when found in the cooler waters of the Great Australian Bight and Tasman Sea.

\section{Phytoplankton species distribution}

Most nanoplankton and also many diatom and dinoflagellate species were found throughout the northern coasts of Australia, from the Coral Sea into the Indian Ocean (Fig. 22). The diatoms Bacteriastrum, Chaetoceros and Rhizosolenia exhibited great abundance and species diversity in continental shelf waters but were less abundant in the offshore Coral Sea and Indian Ocean. A few dinoflagellate species were more restricted in their distribution: Ceratium dens and Dinophysis miles were found only in shelf waters, and Citharistes apsteinii, Gonyaulax birostris and Histioneis spp. only in open ocean environments.

\section{Non-photosynthetic dinoflagellates}

Examination of living phytoplankton samples under the fluorescence microscope showed that many of the dinoflagellates (33 out of 79 species examined) were non-photosynthetic (Table 7). These included some species of Ceratium, Dinophysis (part Phalacroma) and Oxytoxum and all species of Amphisolenia, Blepharocysta, Citharistes, Diplopsalis s. 1., Histioneis, Ornithocercus, Parahistioneis, Podolampas, Protoperidinium and Triposolenia. Photosynthetic species of Ceratium and Dinophysis were often very weakly pigmented, and sometimes dinoflagellate fluorescence varied even within a single species. For example, Ceratocorys horrida showed intensely pigmented redfluorescent cells in shelf waters and non-pigmented green fluorescent cells at offshore stations. A few partly fluorescent cells were also seen.

\section{DISCUSSION}

Phytoplankton biomass. The phytoplankton chlorophyll concentrations of the continental shelf waters of northern Australia (Table 2) are significantly higher than those of other parts of the Eastern Indian Ocean. Chlorophyll values in the productive Java upwelling area are up to $0.85 \mu \mathrm{g} \mathrm{l}^{-1}$ with a water column total of 30 to $40 \mathrm{mg} \mathrm{m}^{-2}$, but offshore waters of the Indian Ocean generally contain chlorophyll levels $<0.15 \mu \mathrm{g} \mathrm{l}^{-1}$ and water column totals of only 15 to 20 $\mathrm{mg} \mathrm{m}^{-2}$ (recalculated values from Humphrey, 1966 and Humphrey and Kerr, 1969). Several mechanisms have been proposed for nutrient enrichment of North Australian continental shelf waters. These include inflow from the Banda Sea upwelling area and nutrient regeneration from bottom sediments in the Gulf of Carpentaria (Forbes, in press) and tidally induced internal waves interacting with the bottom slope on the North-West Shelf (Baines, 1981).

Phytoplankton pigment composition. The chromatographic pigment analyses (Fig. 3; Table 4) indicate that diatoms, golden-brown flagellates and green flagellates are the major planktonic primary producers in northern Australian tropical shelf waters. The low concentrations of the dinoflagellate carotenoid peridinin suggest that photosynthesis by dinoflagellates is insignificant. This is confirmed by the absence of fluorescent chloroplasts in most of these cells (Table 7) and the observations of only weakly pigmented photosynthetic species. It would be of considerable interest to establish to what extent some dinoflagellate species can switch from an autotrophic to a heterotrophic mode of nutrition and if this is accompanied by reversible chloroplast resorption and regeneration. Degenerate plastids or protoplastids have been reported in the non-photosynthetic Cryptothecodinium cohnii (Kubai and Ris, 1969).

Importance of the nanoplankton. Nanoplankton is a major component of tropical phytoplankton, accounting for 70 to $97 \%$ of the total chlorophyll, except in local diatom and Trichodesmium blooms in shallow (20 to $70 \mathrm{~m}$ ) inshore waters where only 30 to $60 \%$ of the chlorophyll biomass is nanoplankton (Table 3). The importance of these small organisms in the tropical Indian Ocean has been suggested previously from fractionated carbon, photosynthesis and chlorophyll measurements (Saijo, 1964; Mullin, 1965; Saijo and Takesue, 1965). In the present work, the quantitative importance of small pennate diatoms, golden-brown flagellates, minute green flagellates and small dinoflagellates was confirmed by light and electron microscopy. Small cyanobacteria in the picoplankton size range $(0.2$ to $2 \mu \mathrm{m})$ have also been recognized and will be described elsewhere. Many nanoplankton species found in the tropical waters $\left(25\right.$ to $\left.30^{\circ} \mathrm{C}\right)$ of the NorthWest Shelf and the Gulf of Carpentaria are also common in subtropical and temperate Australian waters $\left(15\right.$ to $20^{\circ} \mathrm{C}$ ). Species such as Micromonas pusilla and Minidiscus trioculatus, identified in Australian tropical and subtropical waters, have also been recorded from Arctic West Greenland $\left(0\right.$ to $13{ }^{\circ} \mathrm{C}_{i}$ Thomsen, 1982). Tolerance of a wide range of temperatures 
(Throndsen, 1976), or the ability to form strains adapted to different temperature regimes, may contribute to the success of nanoplankton species in the world's oceans.

Diversity of large diatoms and dinoflagellates. In contrast to the nanoplankton, the large tropical diatoms and dinoflagellates are distinctly different from species in subtropical and temperate waters. The main differences are the possession of large spines, horns, setae and wing-like structures in tropical forms, common symbiotic associations and greater species diversity. More than half of the 200 taxa identified (Table 5) can be regarded as tropical species. On the shallow North-West Shelf and in the Gulf of Carpentaria diatoms show the greatest diversity, while in offshore waters of the Indian Ocean and Coral Sea dinoflagellate species are more numerous (Taylor, 1976; Jeffrey and Hallegraeff, unpubl.). Their bizarre shapes may aid flotation, increase nutrient uptake through enhanced rotational movement and greater cell surface area for absorption, and protect against grazing from small zooplankton. Symbiotic associations may benefit both host and symbiont through mutual exchange of organic and inorganic nutrients, but thus far only the Rhizosolenia-Richelia pair has been examined by appropriate microautoradiographic techniques (Taylor, 1982 and references therein). Why tropical phytoplankton exhibit and maintain a high diversity, similar to that of other plants and animals in tropical aquatic and terrestrial habitats, has yet to be answered satisfactorily.

Acknowledgements. The authors are grateful to Dr. M. Vesk, Mr. D. Dwarte and Ms. D. Hughes for advice and technical assistance with the electron microscopy; Mr. J. John and Dr. G. R. Hasle for help with the diatom taxonomy; Ms. M. C. Carbonell, Drs. K. A. Steidinger and F. J. R. Taylor for advice on dinoflagellate taxonomy; and Dr. R. E. Norris and Mr. B. Sundström for assistance with identification of the symbiotic associations. Discussions with Dr. R. E. Norris confirmed our observations that photosynthetic and non-photosynthetic dinoflagellates could be distinguished by fluorescence microscopy. We also thank Mr. R. Griffiths and Mr. N. Dyson for the hydrological analyses.

\section{LITERATURE CITED}

Allen, W. E., Cupp, E. E. (1935). Plankton diatoms of the Java Sea. Annsl Jard. bot. Buitenzorg 44: 101-174

Bain, R. (1982). An overview of the Australian fishing industry. Aust. Fish. 41: 10-15

Baines, P. G. (1981). Satellite observations of internal waves on the Australian North-West Shelf. Aust. J. mar. Freshwat. Res. 32: 457-463

Desrosières, R. (1965). Observations sur le phytoplancton superficiel de l'ocean indien oriental. Cah. ORSTOM, Oceanogr. 3: 31-37

Forbes, A. M. G. (in press). The contribution of local processes to seasonal hydrology of the Gulf of Carpentaria. Oceanographie Tropicale

Hallegraeff, G. M. (1981). Seasonal study of phytoplankton pigments and species at a coastal station off Sydney: importance of diatoms and the nanoplankton. Mar. Biol. 61: $107-118$

Hallegraeff, G. M. (1983), Scale-bearing and loricate nanoplankton from the East Australian Current. Botanica mar. 26: 493-515

Hallegraeff, G. M. (1984). Coccolithophorids (calcareous nanoplankton) from Australian waters. Botanica mar. 27: 229-249

Hallegraeff, G. M., Ringelberg, J. (1978). Characterisation of species diversity of phytoplankton assemblages by dominance - diversity curves. Verh. int. Verein. theor. angew. Limnol. 20: 939-949

Heron, A. C. (1982). A vertical free fall plankton net with no mouth obstructions. Limnol. Oceangr 27: 380-383

Humphrey, G. F. (1966). The concentration of chlorophylls a and $c$ in the South-East Indian Ocean. Aust. J. mar. Freshwat. Res. 17: 135-145

Humphrey, G. F., Kerr, J. D. (1969). Seasonal variations in the Indian Ocean along $110^{\circ} \mathrm{E}$. III. Chlorophylls $a$ and $c$. Aust. J. mar. Freshwat. Res. 20: 55-64

Jeffrey, S. W. (1981). An improved thin-layer chromatographic technique for marine phytoplankton pigments. Limnol. Oceanogr 26: 191-197

Jeffrey, S. W., Hallegraeff, G. M. (1980a). Studies of phytoplankton species and photosynthetic pigments in a warmcore eddy of the East Australian Current. I. Summer populations. Mar. Ecol. Prog. Ser. 3: 285-294

Jeffrey, S. W., Hallegraeff, G. M. (1980b). Studies of phytoplankton species and photosynthetic pigments in a warmcore eddy of the East Australian Current. II. A note on pigment methodology. Mar. Ecol. Prog. Ser. 3: 295-301

Jeffrey, S. W., Humphrey, G. F. (1975). New spectrophotometric equations for determining chlorophylls $a, b, c_{1}$ and $c_{2}$ in higher plants, algae and natural phytoplankton. Biochem. Physiol. Pfl. 167: 191-194

Kubai, D. F., Ris, H. (1969). Division in the dinoflagellate Gyrodinium cohnii Schiller. A new type of nuclear reproduction. J. Cell Biol. 40: 508-528

Major, G. A., Dal Pont., G. Klye, J., Newell, B. S. (1972). Laboratory techniques in marine chemistry: a manual. CSIRO Aust. Div. Fish. Oceanogr. Rep. 51: 1-55

Markina, N. P. (1972). Special features of plankton distribution around northern coasts of Australia during different seasons of 1968-1969 (Russ.). Izv. Tikhvokean nauchnoissled. Inst. ryb. Khoz. Okeanogr. 81: 57-68

Motoda, S., Kawamura, T., Taniguchi, A. (1978). Differences in productivities between the Great Australian Bight and the Gulf of Carpentaria, Australia, in summer. Mar. Biol. 46: 93-99

Mullin, M. M. (1965). Size fractionation of particulate organic carbon in the surface waters of the Western Indian Ocean. Limnol. Oceanogr 10: 459-462

Newell, B. S. (1973). Hydrology of the Gulf of Carpentaria, 1979-1971. CSIRO Aust. Div. Fish. Oceanogr. Tech. Pap. 35: $1-29$

Norris, R. E. (1967). Algal consortisms in marine plankton. In: Krishnamurthy, V. (ed.) Proc. Seminar on Sea, Salt and Plants, 1965. Central Salt and Marine Chemicals Research Institute, Bhavnagar, India, p. 178-189

Rothlisberg, P. C., Jackson, C. J. (1982). Temporal and spatial variation of plankton abundance in the Gulf of Carpentaria, Australia 1975-1977. J. Plankton Res. 4: 19-40

Saijo, Y. (1964). Size distribution of photosynthesizing phyto- 
plankton in the Indian Ocean. J. oceanogr. Soc. Japan 19: 187-189

Saijo, Y., Takesue, K. (1965). Further studies of the size distribution of photosynthesizing phytoplankton in the Indian Ocean. J. oceanogr. Soc. Japan 20: 10-17

Sainsbury, K. J. (1979). CSIRO defining fish stocks on NW Shelf. Aust. Fish. 38: 4-12

Simonsen, R. (1974). The diatom plankton of the Indian Ocean expedition of R. V. 'Meteor' 1964-1965. 'Meteor' Forsch.Ergebn. (D) 19: 1-107.

Smayda, T. J. (1978). From phytoplankters to biomass. In: UNESCO Monographs on oceanographic methodology, No. 6, Phytoplankton manual, p. 273-279

Subrahmanyan, R. (1946). A systematic account of the marine plankton diatoms of the Madras coast. Proc. Indian Acad. Sci. 24 B: $85-197$

Taylor, F. J. R. (1976). Dinoflagellates from the International Indian Ocean Expedition. A report on material collected by the R. VF, 'Anton Bruun' 1963-1964. Biblthca bot. 132: $1-234$.

Taylor, F. J. R. (1982). Symbioses in marine microplankton. Ann. Inst. Oceanogr. 58: 61-90

Thomsen, H. A. (1982). Planktonic choanoflagellates from Disko Bugt, West Greenland, with a survey of the marine nanoplankton of the area. Meddr Grønland (Bioscience) 8: $1-35$

Throndsen, J. (1976). Occurrence and productivity of small marine flagellates. Norw. J. Bot. 23: 269-293

Tranter, D. J., Kerr, J. D. (1977). Further studies of plankton ecosystems in the Eastern Indian Ocean. III. Numerical abundance and biomass. Aust. J. mar. Freshwat. Res. 28: $557-583$

Utermöhl, H. (1958). Zur Vervollkommnung der quantitativen Phytoplankton-Methodik. Mitt. int. Verein. theor. angew. Limnol. 9-38

This paper was submitted to the editor; it was accepted for printing on July 14, 1984 